\title{
Carbamazepine-induced DRESS syndrome leading to reversible myocarditis in a child
}

\author{
MECNUN ÇETIN, MEVSIM DEMIR MIS, KAMURAN KARAMAN, ÍBRAHIM H. YAVUZ, \\ HADI GEYLAN, PERIHAN TUNÇDEMIR, FEYZA DEMIR
}

Yüzüncü Yil University, Turkey

\begin{abstract}
DRESS (drug reaction with eosinophilia and systemic symptoms) syndrome is a rare type of delayed drug hypersensitivity reaction characterised by fever, skin rash, lymphadenopathy, and visceral involvement, which can be life threatening and is a childhood event. An eight-year-old boy was admitted with complaints of extensive rash and fever three weeks after the onset of treatment with carbamazepine for a diagnosis of epilepsy. Fever, as well as patches and plaques with indeterminate limits that tended to merge and were non-blanchable on a widespread erythematous layer, were revealed in physical examination. Extensive cervical, submandibular, and inguinal lymphadenopathy was observed. We present ours as the second case of myocarditis secondary to DRESS syndrome after carbamazepine use in the literature.
\end{abstract}

Key words: carbamazepine, DRESS syndrome, lymphadenopathy, myocarditis.

(Centr Eur J Immunol 2019; 44 (1): 102-105)

\section{Introduction}

Drug reaction with eosinophilia and systemic symptoms (DRESS) syndrome is a rare but life-threatening reaction to drugs such as phenytoin, phenobarbital, carbamazepine, valproate, and allopurinol. The disease is characterized by skin rashes, fever, haematological abnormalities, lymphadenopathy, and organ failure such as hepatic dysfunction [1]. Carbamazepine is widely used as an anti-epileptic agent in paediatric neurology patients. In the literature there have been many reports showing adverse reactions due to the carbamazepine usage. However, there is only one case reported in the literature that shows myocarditis secondary to DRESS syndrome after carbamazepine use [2]. Herein we present ours as the second case of myocarditis secondary to DRESS syndrome after carbamazepine use in the literature.

\section{Case presentation}

The patient was admitted to Yuzuncu Yil University medical faculty paediatric outpatient clinic with complaints of a sudden rash initially on his hands and then spreading all over his body, with a fever of $39^{\circ} \mathrm{C}$ and pruritus about a week earlier. The patient was admitted to our hospital in Van, Turkey in January 2017. Our hospital is a university referral hospital that serves about one million people. The hospital has 670 beds with six paediatric clinical sections. The patient was an eight-year-old boy. On his medical history, carbamazepine was started due to a diagnosis of epilepsy about four weeks earlier. In the patient's physical examination a temperature of $39.2^{\circ} \mathrm{C}$, heart rate of 123 beats/minute, respiratory rate of 23 breaths/minute, blood pressure of $105 / 60 \mathrm{mmHg}$, and $\mathrm{O}_{2}$ saturation of $95 \%$ were measured. There were common millimetric lymph nodes in bilateral cervical and inguinal regions. There were patches and plaques with indeterminate limits that tended to merge and were non-blanchable on a widespread erythematous layer in the physical examination (Fig. 1).

In the laboratory review of the patient the following were reported: no hepatosplenomegaly was observed,
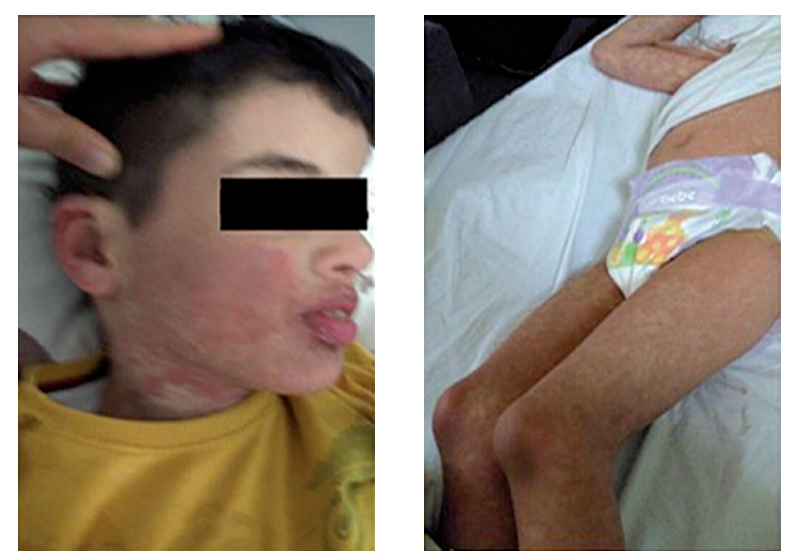

Fig. 1. Common rash on entire body 


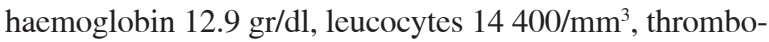
cytes $433000 / \mathrm{mm}^{3}, 30 \%$ neutrophil in peripheral spread, $12 \%$ stab neutrophil, $44 \%$ lymphocytes, $4 \%$ monocytes, $16 \%$ eosinophil, total eosinophil count $2300 / \mathrm{mm}^{3}$, AST $72 \mathrm{IU} / \mathrm{l}$, troponin I $1.7 \mathrm{ng} / \mathrm{ml}$ (normal value: $<0.04 \mathrm{ng} / \mathrm{ml}$ ), CK-MB $725 \mathrm{ng} / \mathrm{ml}$, and CRP $21 \mathrm{mg} / \mathrm{dl}$. Serological studies of Epstein-Barr virus, cytomegalovirus, human immunodeficiency virus, hepatitis A, B, and C, and mycoplasma were normal. Chest radiography was normal. Electrocardiography revealed sinus tachycardia. Table 1 shows the clinical characteristics and variables of our case. An echocardiogram revealed global hypokinesis, mild mitral regurgitation, and decreased contractility (LV ejection fraction $47 \%$, fractional shortening $23 \%$ ) consistent with the diagnosis of myocarditis (Fig. 2). A skin biopsy was performed, which demonstrated an inflammatory infiltrate that was predominantly perivascular and lymphocytic in nature (Fig. 3).

The patient was diagnosed with DRESS syndrome and secondary myocarditis, according to both the biopsy results and the RegiSCAR study group scoring system criteria in Table 2. He was treated with methylprednisolone $2 \mathrm{mg} / \mathrm{kg} /$ day and diphenhydramine $1 \mathrm{mg} / \mathrm{kg}$ i.v. q6h. After carbamazepine was discontinued and the second day of the initiation of the treatment, the clinical symptoms and the general condition improved. Eruptions were completely resolved within seven days. The patient received a total of 45 days of steroid treatment. After two months, echocardiogram showed normal cardiac contractility.

\section{Discussion}

DRESS syndrome, which is a drug eruption syndrome accompanied by eosinophilia and systemic symptoms, is a febrile dermatosis with cutaneous and visceral organ involvement that can develop in both paediatric and adult patients, which is a rare condition among drug eruptions, and it can be fatal [1]. For the first time, in 1950 Chaiken et al. reported a case of fever, morbilliform rash, and hepatitis developing in a patient using phenytoin, and they named the illness phenytoin hypersensitivity. Then in 1996, Bocquet et al. defined it as DRESS, an abbreviation based on clinical and laboratory findings [3].

Although the aetiology of DRESS syndrome is not fully understood, many drugs are blamed, but it is thought to be a drug reaction that is most often caused by aromatic anticonvulsants [4-6]. Yang et al. reported that carbamazepine and phenytoin, which are anticonvulsant medications, were responsible for $43.6 \%$ of all DRESS syndrome cases [7]. Patients with a genetic predisposition develop a severe hypersensitivity reaction within two months of using these drugs (average of 2-6 weeks), and this reaction continues for a long time.

Enzyme defects related to drug metabolism, lymphocyte activation, eosinophilia, and viral agents (especially human herpes virus-6 and -7, EBV, and HIV) are reported to be
Table 1. The clinical characteristics and variables of our case

\begin{tabular}{l}
\hline Carbamazepine use \\
\hline Acute rash on whole body \\
\hline Pruritus \\
\hline Fever above $38^{\circ} \mathrm{C}$ \\
\hline Enlarged lymph nodes in bilateral cervical and inguinal regions \\
\hline Blood count parameters \\
Leucocytosis \\
Eosinophilia
\end{tabular}

Elevated serum aspartate aminotransferase (AST), troponin I, CK-MB, and C-reactive protein (CRP) levels

Echocardiographic abnormalities (global hypokinesis, mild mitral regurgitation, and decreased contractility)

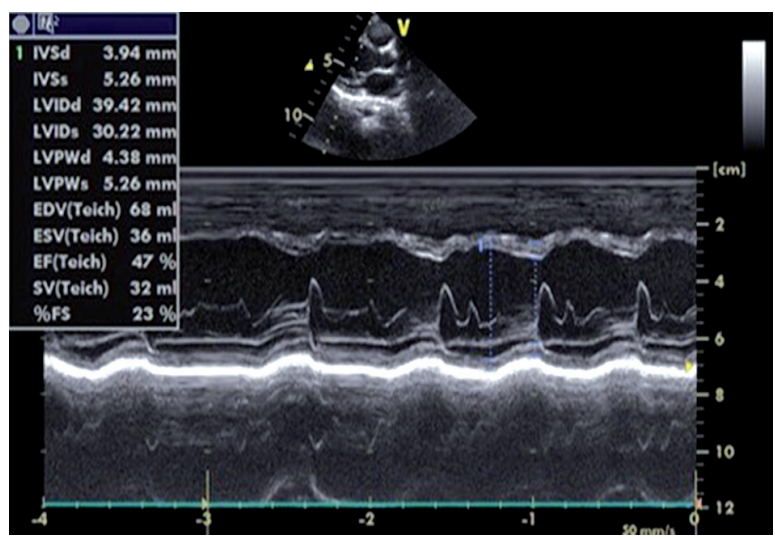

Fig. 2. M-mode echocardiography showing systolic dysfunction

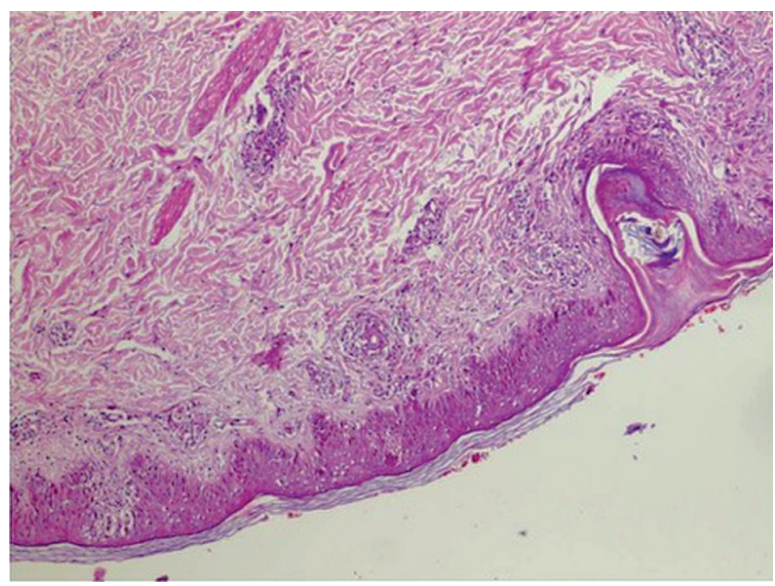

Fig. 3. Showed various degrees of basal vacuolization, dyskeratosis, infiltration of the epidermis by lymphocytes, dermal edema, superficial perivascular inflammation 
responsible for the aetiopathogenesis. DRESS syndrome associated with aromatic anticonvulsant drugs is thought to arise from a pharmacogenetic defect in the epoxide hydroxylase enzyme system, which is involved in drug detoxification. Also, increased reactive metabolites after detoxification failure are thought to cause an immunological reaction. Because aromatic anticonvulsant drugs (phenytoin, phenobarbital, carbamazepine) are metabolised in the same way, the potential cross-reaction risk between these drugs is reported to be between $40 \%$ and $80 \%$ [8].

In this syndrome, fever, rash, lymphadenopathy, haematological abnormalities (eosinophilia, lymphocytosis), hepatosplenomegaly, and hepatitis can be seen. DRESS syndrome is a type 4 hypersensitivity reaction, and type 2 T-helper cells play a role in the occurrence of this disease. Skin lesions can be seen, from a broad spectrum of diffuse maculopapular rashes to erythroderma, and rarely Stevens-Johnson syndrome and toxic epidermal necrosis [9].

Although systemic involvement of the liver, kidney, and lymph nodes is frequently observed in this syndrome, pulmonary and cardiac involvements are rarely reported. Liver and kidney involvement may result in ALT, AST elevation, hypoalbuminaemia, proteinuria, and haematuria. Eosinophilia can be seen frequently in the blood count $[9,10]$.

In our case, a common rash over the whole body, fever, and diffuse lymphadenopathy, which is an important criterion of DRESS syndrome, were present three weeks after carbamazepine usage. Liver function tests, such as ALT, AST, and cardiac involvement markers including CK-MB and troponin I value, were found to be high. There was leukocytosis in the blood count and marked eosinophilia in peripheral spread. Although renal function tests and chest X-ray were normal, myocardial systolic dysfunction and mild mitral failure, which pointed to myocarditis, were observed on echocardiography examination. A literature search revealed that Lo et al. reported the first case of a 14-year-old girl in the paediatric population, who developed myocarditis after carbamazepine use [2]. Ours is the second case in the literature to present myocarditis that developed after carbamazepine use in a paediatric patient.

Diagnostic criteria defined by the RegiSCAR study group and the Japanese consensus group are used for the diagnosis of DRESS syndrome. In addition, diagnostic criteria are also defined by Bocquet et al. To meet the DRESS definition, patients must have three of the four main RegiSCAR criteria in Table 2. The Japanese consensus group developed a second diagnostic criterion group. According to these criteria, seven of the criteria in Table 2 or all of the first five criteria must be present for the diagnosis $[3,6]$. We could not study HHV-6, the first criterion of the Japanese consensus group as seen in Table 2, but our case met the remaining criteria. In addition, our case met all of the RegiSCAR study group scoring system criteria. According to these criteria, the case was diagnosed as DRESS syndrome and secondary myocarditis.

Treatment of DRESS syndrome includes discontinuation of the underlying agent and application of corticosteroids, and supportive care. Intravenous immunoglobulin is not routinely recommended; nevertheless, for patients with myocarditis, intravenous immunoglobulin should be considered [11]. Myocarditis is a potentially fatal complication of a drug reaction with eosinophilia and systemic symptoms. Early recognition and treatment with corticosteroids may improve clinical outcomes. We used corticosteroid and supportive treatment for the presence of cardiac involvement, and we had a rapid clinical response. We did not need IVIG treatment because the myocarditis findings were not severe and there were no life-threatening clinical findings.

Table 2. Diagnostic criteria for DRESS syndrome [3]

\begin{tabular}{|c|c|c|}
\hline Borquet et al. & RegiSCAR study group & Japanese consensus group \\
\hline $\begin{array}{l}\text { DRESS is confirmed by presence of } 1 \text { and } 2 \text { and } 3 \\
\text { 1. Cutaneous drug eruption } \\
\text { 2. Adenopathies }>2 \mathrm{~cm} \text { in diameter of hepatitis } \\
\text { (liver transaminases }>2 \text { times upper limit of } \\
\text { normal) (or) interstitial nephritis (or) interstitial } \\
\text { pneumonitis (or) carditis } \\
\text { 3. Haematological abnormalities; eosinophilia } \\
>1.5 \times 10^{9} / 1 \text { (or) atypical lymphocytes }\end{array}$ & $\begin{array}{l}\text { More than } 3 \text { of the criteria are required for } \\
\text { the diagnosis of DRESS } \\
\text { 1. Hospitalisation } \\
\text { 2. Reaction suspected to be drug related } \\
\text { 3. Acute rash } \\
\text { 4. Fever above } 38^{\circ} \mathrm{C} \\
\text { 5. Enlarged lymph nodes involving } \\
\text { at least two sites } \\
\text { 6. Involvement of at least one internal } \\
\text { organ } \\
\text { 7. Blood count abnormalities } \\
\text { Lymphocytes above or below } \\
\text { laboratory limits } \\
\text { Eosinophils above laboratory limits } \\
\text { (in percentage or absolute count) } \\
\text { Platelets below laboratory limits }\end{array}$ & $\begin{array}{l}\text { Typical DRESS (presence of all } \\
7 \text { criteria): atypical DIHS (all criteria } \\
\text { present except lymphadenopathy and } \\
\text { HHV-6 reactivation) } \\
\text { 1. HHV-6 reactivation } \\
\text { 2. Prolonged clinical symptoms } 2 \text { weeks } \\
\text { after discontinuation of causative drug } \\
\text { 3. Maculopapular rash developing } \\
>3 \text { weeks after starting drug } \\
\text { 4. Fever above } 38^{\circ} \mathrm{C} \\
\text { 5. Lymphadenopathy } \\
\text { 6. ALT > } 100 \text { U/l or other organ } \\
\text { involvement } \\
\text { 7. Leukocyte abnormalities (at least one) } \\
\text { Leucocytosis }\left(>11 \times 10^{9} / 1\right) \\
\text { Atypical lymphocytosis }(>5 \%) \\
\text { Eosinophilia }\left(1.5 \times 10^{9} / 1\right)\end{array}$ \\
\hline
\end{tabular}

DRESS - drug rash with eosinophilia and systemic symptoms, RegiSCAR - European registry of severe cutaneous adverse reactions, DIHS - drug-induced hypersensitivity syndrome, $H H V-6$ - human herpesvirus 6 , ALT - alanine aminotransferase 
In conclusion, DRESS syndrome is an uncommon drug reaction in childhood, which could be fatal if not treated. It should be considered in the differential diagnosis of patients with common rash with medication use in anamnesis. Although DRESS syndrome is rare, it is a clinical condition that should be considered as a fatal disease in cases of reuse of the same group of drugs, and it should be promptly recognised and dealt with because of frequent use of the anticonvulsants in many diseases. We think that reporting this case is important because DRESS syndrome is seen very rarely, and ours is the second case with cardiac involvement in the literature.

The authors declare no conflict of interest.

\section{References}

1. Ferrero NA, Pearson KC, Zedek DC, Morrell DS. Case report of drug rash with eosinophilia and systemic symptoms demonstrating human herpesvirus-6 reactivation. Pediatr Dermatol 2013; 30: 608-613.

2. Lo MH, Huang CF, Chang LS, et al. Drug reaction with eosinophilia and systemic symptoms syndrome associated myocarditis: a survival experience after extracorporeal membrane oxygenation support. J Clin Pharm Ther 2013; 38: 172-174.

3. Husain Z, Reddy BY, Schwartz RA. DRESS syndrome: Part I. Clinical perspectives. J Am Acad Dermatol 2013; 68: 693.

4. Cacoub P, Musette P, Descamps V. The DRESS syndrome: A literature review. Am J Med 2011; 124: 588-597.

5. Knowles SR, Dewhurst N, Shear NH. Anticonvulsant hypersensitivity syndrome: An update. Expert Opin Drug Saf 2012; 11: 767-778.

6. Kardaun SH, Sekula P, Valeyrie-Allanore L, et al.; RegiSCAR study group. Drug reaction with eosinophilia and systemic symptoms (DRESS): An original multisystem adverse drug reaction. Results from the prospective RegiSCAR study. Br J Dermatol 2013; 169: 1071-1080.

7. Yang CY, Dao RL, Lee TJ, Lu CW, Yang CH, Hung SI, Chung WH. Severe cutaneous adverse reactions to antiepileptic drugs in Asians. Neurology 2011; 77: 2025-2033.

8. Criado PR, Avancini J, Santi CG, et al. Drug reaction with eosinophilia and systemic symptoms (DRESS): A complex interaction of drugs, viruses and the immune system. Isr Med Assoc J 2012; 14: 577-582.

9. Peyričre H, Dereure O, Breton H, et al. Network of the French Pharmacovigilance Centers. Variability in the clinical pattern of cutaneous side-effects of drugs with systemic symptoms: does a DRESS syndrome really exist? Br J Dermatol 2006; 155: 422-428.

10. Darban M, Bagheri B. Drug reaction with eosinophilia and systemic symptoms induced by valproic acid: a case report. Iran Red Crescent Med J 2016; 18: e36825.

11. Ho CH, Uzunyan MY. Myocarditis in drug rash with eosinophilia and systemic symptoms. Cardiol Young 2015; 25: 1210-1213. 